\title{
The challenge of the Predatory Open-access Publishing Epidemia
}

Andrea Cortegiani ${ }^{1}, M D$, Giovanni Misseri ${ }^{1}, M D$, Cesare Gregoretti ${ }^{1}$, Sharon Einav $^{2}, \mathrm{MD}$, Antonino Giarratano ${ }^{1} \mathrm{MD}$

${ }^{1}$ Department of Surgical, Oncological and Oral Science (Di.Chir.On.S.). Section of Anesthesia, Analgesia, Intensive Care and Emergency. Policlinico Paolo Giaccone.

University of Palermo, Italy

${ }^{2}$ Intensive Care Unit of the Shaare Zedek Medical Medical Centre and Hebrew University Faculty of Medicine, Jerusalem, Israel

Andrea Cortegiani: cortegiania@gmail.com

Giovanni Misseri: giovannimisseri1987@gmail.com

Cesare Gregoretti: c.gregoretti@gmail.com

Sharon Einav: einav_s@szmc.org.il

Antonino Giarratano: antonino. giarratano@unipa.it

Corresponding author: Andrea Cortegiani, MD

Department of Surgical, Oncological and Oral Science (Di.Chir.On.S.). Section of Anesthesia, Analgesia, Intensive Care and Emergency. Policlinico Paolo Giaccone. University of Palermo, via del vespro 129, 90127, Palermo, Italy. Email:

cortegiania@gmail.com; Phone: +390916552718

Competing interest: None

Funding: None

Acknowledgement: None 
Author contribution: All authors contributed equally to the conception, writing and correcting the proof of the manuscript. All authors read and approved the final version of the manuscript.

Word count: 1007

\section{MAIN TEXT}

\section{BACKGROUND}

Predatory open-access (OA) publishing is nowadays one of the most threatening infectious disease affecting scientific research and Science credibility [1]. Although there is not a universally accepted definition, predatory OA publishing is mainly characterized by lack of scientific rigor of a fraudulent OA model that applies charges to the authors under the pretense of legitimate publishing operations without providing adequate editorials services, leading to poor or non-existent peer-review process and editorial ethics $[1,2]$. This detrimental practice has been also linked to email spamming to scholars for manuscript submissions, indiscriminate invitation to join editorial board and fake conferences, stolen editorial identities and unethical attempt to inflate curricula.

Knowledge about this complex disease among researchers and clinicians is low and may be the only way to counteract the ongoing epidemia [2].

\section{EPIDEMIOLOGY}

The spread of Predatory OA publishing is epidemic. Shen et al identified 1.800 predatory journals and 53.000 published papers in 2010 and a nearly five- and eight-fold increase respectively in 2015 with an increasing trend [3]. All scientific areas seem to be infected, including biomedical fields and in particulate intensive Care Medicine. A recently published study specifically demonstrated that the number of potential predatory journals $(n=212)$ was more than double the number of legitimate journals in the field of 
Anaesthesiology in the SCIMAGO journal rank $(n=106)$ [2] [4]. The total number of published articles in potential predatory journals was 12.871 and the median requested article processing charge (APC) by these journals was 634.5 USD [2].

The profile of the authors who published in or cite from predatory journals seems related to young inexperienced scholars from developing countries [5]. Africa (i.e. Nigeria, South Africa) and Asia (i.e. China, India, Pakistan, Malaysia) seem to be deeply affected [6]. However, data demonstrated that $5 \%$ of a sample of 46.000 researchers seeking promotion from Italy [7] and over 5.000 researchers from Germany published in potentially predatory journals, which were the editorial targets for around $6 \%$ of scientific papers from the United States [3].

\section{PATHOPHISYOLOGY}

Although complex, pathophysiological mechanisms can be linked, at least in part, to the "publish or perish" rush, which may drive academic promotions, and to the attracting promises of fraudulent publishers for an easier way to publish. Lack of serious scientific mentorship and traditions, and less control by policymakers may explain the geographic difference of the disease. However, the rush to increase personal bibliometric data and to push curricula (i.e. editorial board membership) can lead to the addiction to predatory publishing even in respectful organizations for prestigious positions and for fund rising [8].

\section{CONSEQUENCES}

Low quality research without editorial control can be detrimental for medical practice since inexperienced clinicians can use these data or information in their clinical practice. Other researchers may use flawed data from these journals for new (flawed!) research hypothesis or further analyses. Academic 
promotions and fund rising may be achieved with the help of the detrimental practice of predatory publishing [5]. Predatory publishing is also an "hot topic" on the general and social media undermining the reputation of Science to general public [5]. Lastly, stolen identity for fake Editorial board membership may be detrimental for respectful scholars (usually 'opinion leaders') who can be unaware of this issue.

\section{DIAGNOSIS}

The differential diagnosis between predatory and legitimate journals is sometime difficult to achieve. The diagnosis has been based for many years on the Beall list, which was a blacklist handled by prof. Jeffrey Beall including 'potential probable and possible predatory OA publishers and journals' basing on International Journal of Medical Journals Editors (ICMJE) [9]. The list was shut down in 2016 after being heavily criticized for subjectivity, low specificity and lawsuits by some publishers. The list was used for several investigations on this topic and has been updated by anonymous researchers [9].

Moving out from the concept of "blacklist", the diagnosis should nowadays be based on the ability of researchers to check characteristics of journals and publishers that must be taken into account (Figure 1) $[2,4,10]$. The most reliable findings that should rise suspect are: fake reported location of the journal office (i.e. not credible location of editorial offices after checking by Google street view); English form (on websites and spam emails); mimicking the name of a legitimate journal; limited or absent information on article processing chargers (APC), manuscript handling process ethics rule and editorial policy; constant invitation to join reviewers' or editorial board in promotional email or websites; undue promotion of the fake indexing or metrics (e.g. Global Impact Factor, Index Copernicus etc.) or fake impact factor $[2,11]$. 
Predatory journals colonize major databases since some predatory journals are indexed in Pubmed, Scopus and Google Scholar [12]. So the inclusion of a journal into these databases should not be considered a proof of legitimacy. The Directory of Open Access journals (DOAJ) seems to have the best specificity for inclusion of predatory publishers and journals among major directories and databases due to the stringent criteria for registration [13].

\section{THERAPEUTIC MANAGEMENT}

Produced with the support of several scientific organizations (Committee on Publication Ethics - COPE, Open Access Scholarly Publishers Association) and legitimate publishers, the Think. Check. Submit. campaign "aims to educate researchers, promote integrity and build trust in credible research and publications" [14]. This checklist guides scholars to assess legitimacy of journals trough a step-by-step process [14,15]. Moreover, in 2012, the San Francisco Declaration on Research Assessment (DORA) has been developed with the aim to promote best practice in scholarly research involving different disciplines and all contributors to scientific research [16]. The aims of the declaration include to move from quantity to quality, with less importance on "metrics", for research evaluation, fund rising and promotions.

\section{CONCLUSION}

The epidemic spread of predatory OA publishing is a serious threat for scientific community and, potentially, to patients safety. As always in Medicine, countermeasures should start from a deep knowledge about pathophysiology of the disease and should not be limited to scholars education but also to organizations, publishers and academia 


\section{FIGURE LEGEND}

Figure 1. Tips to apply before submitting a manuscript to a journal to avoid potential predatory publisher and journals. DOAJ: Directory of Open Access journals; APC: Article processing charges; IF: Impact Factor

\section{LIST OF ABBREVIATION}

OA: open-access

APC: article processing charges

ICMJE: International Journal of Medical Journals Editors

DOAJ: Directory of Open access Journal

DORA: San Francisco Declaration on Research Assessment

COPE: Committee on Publication Ethics

\section{REFERENCE}

1. Beall J. Predatory publishers are corrupting open access. Nature. 2012;489:179.

2. Cortegiani A, Longhini F, Sanfilippo F, Raineri SM, Gregoretti C, Giarratano A. Predatory Open-Access Publishing in Anesthesiology. Anesth Analg. 2019;128:182-7.

3. Shen C, Bjork B-C. "Predatory" open access: a longitudinal study of article volumes and market characteristics. BMC Med. 2015;13:230.

4. Cortegiani A, Sanfilippo F, Tramarin J, Giarratano A. Predatory openaccess publishing in critical care medicine. J Crit Care. 2019;50:247-9.

5. Perlin MS, Imasato T, Borenstein D. Is predatory publishing a real threat? Evidence from a large database study. Scientometrics. 2018;116:255-73. 
6. Xia J, Harmon JL, Connolly KG, Donnelly RM, Anderson MR, Howard HA. Who publishes in "predatory" journals? Journal of the Association for Information Science and Technology. 2015;66:1406-17.

7. Bagues M, Sylos-Labini M, Zinovyeva N. A walk on the wild side:"Predatory"journals and information asymmetries in scientific evaluations. Research Policy. Elsevier; 2019;48:462-77.

8. Pond BB, Brown SD, Stewart DW, Roane DS, Harirforoosh S. Faculty Applicants' Attempt to Inflate CVs Using Predatory Journals. American journal of pharmaceutical education. American Journal of Pharmaceutical Education; 2019;83:7210-0.

9. https://beallslist.weebly.com/.

10. Cortegiani A, Garofalo E, Bruni A, Sanfilippo F, Longhini F. Predatory Open-Access Publishing in Palliative and Supportive Care. J Pain Symptom Manage. 2019;57:e1-e3.

11. Shamseer L, Moher D, Maduekwe O, Turner L, Barbour V, Burch R, et al. Potential predatory and legitimate biomedical journals: can you tell the difference? A cross-sectional comparison. BMC Med. 2017;15:28.

12. Manca A, Cugusi L, Dvir Z, Deriu F. PubMed should raise the bar for journal inclusion. Lancet. 2017;390:734-5.

13. https://doaj.org/.

14. http://thinkchecksubmit.org/.

15. Cortegiani A, Shafer SL. "Think. Check. Submit." to avoid predatory publishing. Crit Care. 2018;22:300.

16. https://sfdora.org/. 